\title{
A CORRELATIVE STUDY OF ANTHROPOMETRIC AND ELECTROPHYSIOLOGICAL DATA OF PATIENTS WITH CARPAL TUNNEL SYNDROME ATTENDING THE DEPARTMENT OF PHYSICAL MEDICINE AND REHABILITATION OF A TERTIARY CARE HOSPITAL
}

\author{
Santhosh Kothirappallil Raghavan', Roy Rama Chandran², Charvakan Suthan³, Mitu Chirakkalthazhath Shankar", Dhanya Raj ${ }^{5}$
}

${ }^{1}$ Associate Professor, Department of Physical Medicine and Rehabilitation, Government T. D. Medical College, Alappuzha. ${ }^{2}$ Assistant Professor, Department of Physical Medicine and Rehabilitation, Government T. D. Medical College, Alappuzha. ${ }^{3}$ Assistant Professor, Department of Physical Medicine and Rehabilitation, Government T. D. Medical College, Alappuzha. ${ }^{4}$ Senior Resident, Department of Physical Medicine and Rehabilitation, Government T. D. Medical College, Alappuzha.

${ }^{5}$ Lecturer, Department of Physical Medicine and Rehabilitation, Government T. D. Medical College, Alappuzha.

\section{ABSTRACT}

\section{BACKGROUND}

Carpal Tunnel syndrome is the most common entrapment neuropathy of upper limb. The established diagnostic tool for CTS is an electrodiagnostic study, which requires sophisticated machine and trained personnel to perform the study. Hence, in this study, we have made an attempt to test the significance of a simple screening tool based on wrist ratio (Johnson's index) $\geq 0.7$ and CTS. Wrist ratio is determined by dividing Thickness (T) of wrist at the level of distal crease by wrist width (W) at the same level and this ratio is correlated with median nerve sensory latencies among the patients presented with clinical features suggestive of CTS. Hence, $\mathrm{T} / \mathrm{W}$ ratio can be used as a screening tool during pre-placement examinations of jobs that are prone to cause CTS.

\section{MATERIALS AND METHODS}

The institutional ethical committee has granted permission for the study and subsequently 50 cases of CTS based on clinical grounds are selected from outpatient unit of the Department of Physical Medicine and Rehabilitation of a tertiary care hospital from April 2016 to September 2016. Patients with features of Peripheral neuropathy, Cervical radiculopathy and toxic neuropathy are excluded. Among the selected patients, after getting an informed consent, T/W ratio of dominant hands is determined by using a standard Vernier-Calliper and later they are subjected to standard Electrodiagnostic procedures. Reference values for each parameter was taken from the standard text books. All the data were entered in Microsoft excel sheet, rechecked and analysed with SPSS16 version statistical software. For categorical variables, Chi square test and for continuous variables, descriptive analysis was used in statistical analysis.

\section{RESULTS}

In this study, out of 50 cases, 44 were female (88\%) and 6 were male (12\%) with F:M ratio 7.3:1 Age group ranged from 21 - 62 years with a mean age of 40.5 . T/W ratio $\geq 0.7$ in $46(92 \%)$ and $<0.7$ in $4(8 \%)$ noted. In the T/W ratio $\geq 0.7$ category, Median nerve DL was $>3.3$ (Group a) in $44(95.7 \%$ ) and $<3.3$ (Group b) in $2(4.3 \%)$ cases. In T/W ratio <0.7 category, Median nerve DL was $>3.3$ (Group c) in $2(50 \%)$ and $<3.3$ (Group d) in $2(50 \%)$ cases. Comparison of variables under each group was done by Chi-square test. Positive correlation was found between Median sensory latencies and T/W ratio $\geq 0.7(\mathrm{p}<0.05)$. Hence, it is proved that $\mathrm{T} / \mathrm{W}$ ratio $\geq 0.7$ has got positive correlation with Median nerve sensory DL $>3.3$.

\section{CONCLUSION}

$\mathrm{T} / \mathrm{W}$ ratio $\geq 0.7$ has got significant correlation with Median nerve $\mathrm{DL}>3.3$. Hence, it can be used as a simple screening tool in the evaluation of patients with suspected CTS.

\section{KEYWORDS}

CTS- Carpal Tunnel Syndrome, T/W Ratio- Thickness/ Width Ratio, DL- Distal Latency.

HOW TO CITE THIS ARTICLE: Raghavan SK, Chandran RR, Suthan C, et al. A correlative study of anthropometric and electrophysiological data of patients with carpal tunnel syndrome attending the Department of Physical Medicine and Rehabilitation of a tertiary care hospital. J. Evolution Med. Dent. Sci. 2017;6(75):5382-5386, DOI: 10.14260/Jemds/2017/1167

\section{BACKGROUND}

Hand is a complex tool with which humans receive information from the external world and then act up on it. In order to execute these functions, hands must be

Financial or Other, Competing Interest: None.

Submission 24-07-2017, Peer Review 05-09-2017,

Acceptance 11-09-2017, Published 18-09-2017.

Corresponding Author:

Dr. Santhosh Kothirappallil Raghavan,

Associate Professor,

Department of Physical Medicine

and Rehabilitation, Government

T. D. Medical College, Alappuzha.

E-mail: dr.santhoshraghavan@gmail.com

DOI: $10.14260 /$ jemds/2017/1167 supple, agile and coordinated. Hence, all diseases and disabling conditions of hands got considerable implications considering the Functional deficits that may result. Early recognition, accurate prognostication and timely management is important in such conditions to prevent/reduce disability. CTS is one of the most common entrapment neuropathy of upper limb that presents with hand numbness and weakness. This condition is one among the repetitive strain injuries (RSI) affecting wrist according to the National Health and Medical Research Council (NHMRC) guidelines. ${ }^{1}$

Electrodiagnostic study of median and ulnar nerves is the established method to diagnose CTS but this method requires sophisticated machine and trained personnel; hence 
developing a simple anthropometric ratio as a screening tool for CTS is useful for identification of people who are prone to this common condition.

In this study titled "A correlative study of anthropometric and electrophysiological data of Carpal Tunnel Syndrome", an earnest effort is being made to find the statistical correlation of thickness/width ratio of wrist (T/W ratio) or Johnson's index $\geq 0.7$ and Median nerve distal latency among clinically confirmed cases of carpal tunnel syndrome. Thus, $\mathrm{T} / \mathrm{W}$ ratio measurement is to be made a mandatory pre-placement screening tool for all jobs with CTS preponderance. Normal $\mathrm{T} / \mathrm{W}$ ratio is $<0.7$, called as rectangular wrists, but when the wrist thickness increases it becomes circular and $\mathrm{T} / \mathrm{W}$ ratio will be $\geq 0.7$. Such circular wrists are more associated with CTS.

\section{Objective}

To identify the statistical correlation between $\mathrm{T} / \mathrm{W}$ ratio of wrist $\geq 0.7$ and Median sensory DL $>3.3$ among clinically documented cases of Carpal tunnel syndrome.

\section{MATERIALS AND METHODS}

It is an observational study done on clinically documented fifty cases of CTS attending the Outpatient department of Physical Medicine and Rehabilitation, Government T. D. Medical College, Alappuzha from April 2016 to September 2016. Those presented with pain and numbness in the lateral three and half fingers of hand with nocturnal exacerbation of symptoms and a positive wrist flexion test (Phalen's test) were included in the study. Patients with features of cervical radiculopathy, peripheral neuropathy and thoracic outlet syndrome are excluded. Clearance from the Institutional Ethics Committee was obtained and after getting an informed consent, patients are included in the study. A standard Vernier- Calliper was used for taking wrist thickness (T) and Width (W) measurement of the dominant hand and thus T/W ratio was calculated. Then, they are divided in to two groups, one with $\mathrm{T} / \mathrm{W}$ ratio $\geq 0.7$ and the other with $<0.7$.

A standard EMG/NCS machine with appropriate software was used for electrodiagnostic studies. Patients were subjected for electrophysiological studies like motor and sensory studies of both median and ulnar nerves, distal latency of each nerve measured, Median nerve was stimulated at elbow also to exclude proximal compressions. F wave study of Median nerve was performed to exclude C6 Radiculopathy. Ulnar nerves were subjected for both Motor and sensory studies to exclude Peripheral Neuropathy. References for normal values are taken from standard text books. Results of the study were entered in Microsoft excel sheet, rechecked and analysed with SPSS16 version statistical software. For categorical variables, chi square test and for continuous variables, descriptive analysis was used in statistical analysis.

The Two Groups of Patients are subdivided in to Four Groups-

Group a with $\mathrm{T} / \mathrm{W}$ ratio $\geq 0.7$ and Median DL $>3.3$.

Group b with T/W ratio $\geq 0.7$ and Median DL $<3.3$.

Group c with $\mathrm{T} / \mathrm{W}$ ratio $<0.7$ with Median nerve DL $>3.3$.

Group d with $\mathrm{T} / \mathrm{W}$ ratio $<0.7$ and Median $\mathrm{DL}<3.3$.
Comparison of variables under each group was done by Chi-square test.

\section{RESULTS}

The total number of cases studied was fifty.

\begin{tabular}{|c|c|c|}
\hline Females & 44 & $88 \%$ \\
\hline Males & 06 & $12 \%$ \\
\hline Total & $\mathbf{5 0}$ & $\mathbf{1 0 0 \%}$ \\
\hline \multicolumn{2}{|c|}{ Table I. Showing Gender Distribution } \\
\hline
\end{tabular}

$88 \%$ Females.

$12 \%$ Males.

$\mathrm{F}: \mathrm{M}=7.3: 1$

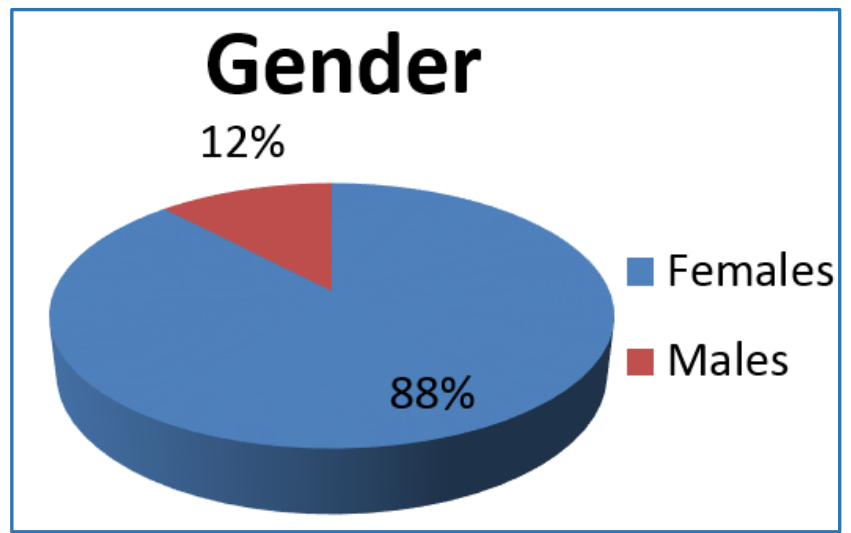

Pie Diagram 1. Showing Gender Distribution

\section{Age Distribution}

In this series, 21 years was the youngest and 62 years was the oldest; Mean age - 40.5 years.

\begin{tabular}{|c|c|}
\hline Age Group & Number \\
\hline $20-30$ & 5 \\
\hline $31-40$ & 16 \\
\hline $41-50$ & 20 \\
\hline $51-60$ & 8 \\
\hline $61-70$ & 1 \\
\hline Total & $\mathbf{5 0}$ \\
\hline \multicolumn{2}{|c|}{ Table II. Showing Age Distribution } \\
\hline
\end{tabular}

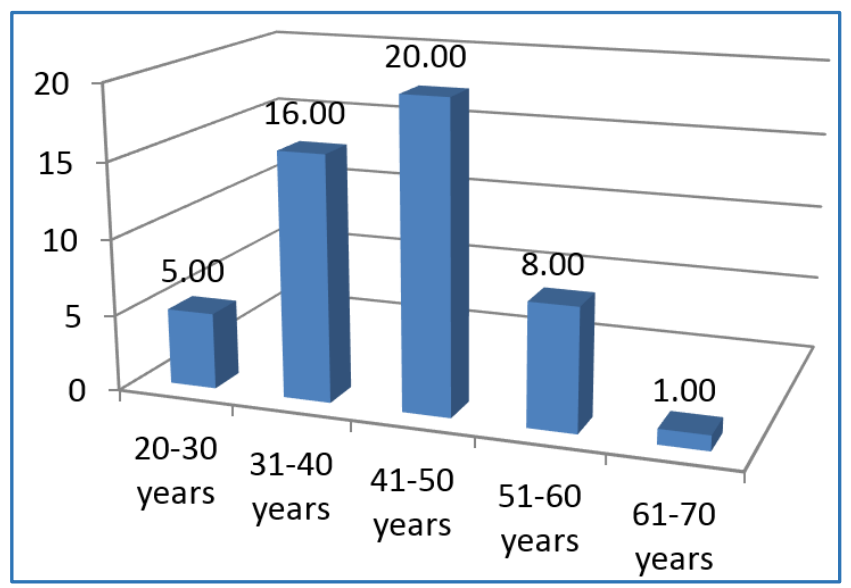

Graph 1. Showing Age Distribution 
Distribution of $\mathrm{T} / \mathrm{W}$ ratio of dominant hands.

\begin{tabular}{|c|c|c|}
\hline T/W ratio $\geq 0.7$ & 46 & $92 \%$ \\
\hline $\mathrm{T} / \mathrm{W}$ ratio $<0.7$ & 4 & $8 \%$ \\
\hline Total & $\mathbf{5 0}$ & $\mathbf{1 0 0} \%$ \\
\hline Table III. showing Distribution of T/W ratio of Dominant \\
Hands
\end{tabular}

In $92 \% \mathrm{~T} / \mathrm{W}$ ratio was $\geq 0.7$ and in $8 \% \mathrm{~T} / \mathrm{W}$ ratio was $<0.7$, p value 0.00 .

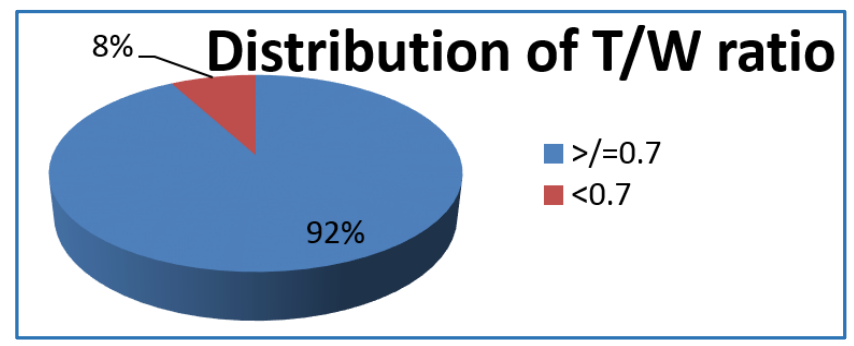

Pie Diagram-2. Showing Distribution of T/W Ratio of Dominant Hands

\begin{tabular}{|c|c|c|}
\hline DL $>3.3$ & 44 & $95.70 \%$ \\
\hline DL $<3.3$ & 2 & $4.30 \%$ \\
\hline Total & $\mathbf{4 6}$ & $\mathbf{1 0 0} \%$ \\
\hline $\begin{array}{c}\text { Table IV. Showing Distribution of Median Nerve } \\
\text { Sensory Latency DL among } \mathbf{T} / \text { W ratio } \geq \mathbf{0 . 7}\end{array}$ \\
\hline
\end{tabular}

\section{DL distribuition}

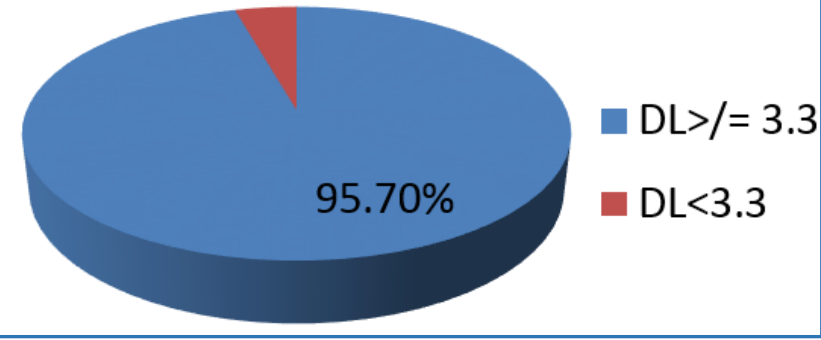

Pie Diagram 3. Showing Distribution of Median Nerve Sensory Latency DL among $T / W$ ratio $\geq 0.7$

\begin{tabular}{|c|c|}
\hline Median sensory DL $\geq 3.3$ & 2 \\
\hline Median sensory $\mathrm{DL}<3.3$ & 2 \\
\hline Total & 4 \\
\hline
\end{tabular}

Hence, $50 \%$ of cases each with significant DL and with insignificant DL.

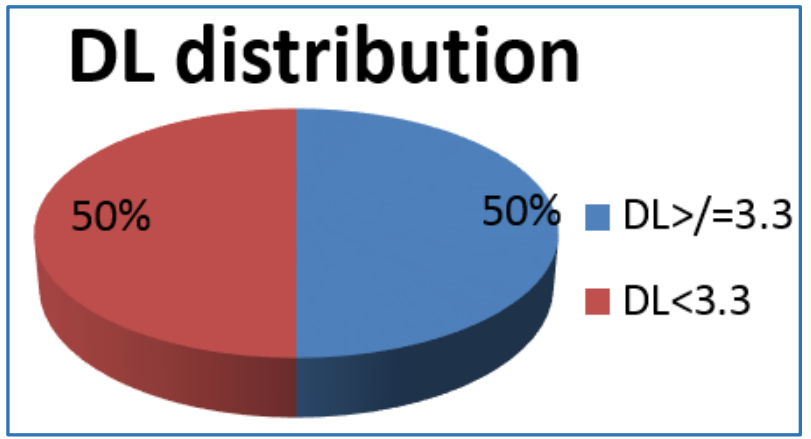

Pie Diagram 4. Showing Distribution of Median Sensory Latency among $T / W$ ratio $<0.7$ Group
Statistical Analysis

Patients are grouped under four groups.

Group a with T/W ratio $\geq 0.7$ and Median DL $>3.3$. Group $\mathrm{b}$ with $\mathrm{T} / \mathrm{W}$ ratio $\geq 0.7$ and Median $\mathrm{DL}<3.3$. Group c with T/W ratio $<0.7$ and Median DL $>3.3$. Group d with T/W ratio $<0.7$ and Median DL $<3.3$.

Comparison of categorical variables under each group was done by Chi-square test.

\begin{tabular}{|c|c|c|c|}
\hline \multirow{2}{*}{ T/W Ratio } & \multirow{2}{*}{ Number } & $\begin{array}{c}\text { DL of Median } \\
\text { Nerve SNAP }\end{array}$ & $\begin{array}{c}\text { DL of Median } \\
\text { Nerve SNAP }\end{array}$ \\
\cline { 3 - 4 } & & $\geq 3.3$ & $<3.3$ \\
\hline$\geq 0.7$ & 46 & $44(\mathrm{a})$ & $2(\mathrm{~b})$ \\
\hline$<0.7$ & 4 & $2(\mathrm{C}$ & $2(\mathrm{~d})$ \\
\hline Total & $\mathbf{5 0}(\mathrm{n})$ & $\mathbf{4 6}$ & $\mathbf{4}$ \\
\hline \multicolumn{3}{|c|}{$\begin{array}{c}\text { Table VI. Showing Distribution of } \\
\text { Variables under Various Categories }\end{array}$} \\
\hline \multicolumn{4}{|c|}{} \\
\hline
\end{tabular}

By applying values of respective variables from the chart in the chi-square formula a value of 5.14 is obtained.

Finding the degree of freedom (d.f).

d.f $=(c-1) 9 r-1)$, where ' $c$ ' stands for number of columns and ' $r$ ' stands for number of rows.

$=(2-1)(2-1)$

$=1$

\section{Probability Tables}

Based on the published probability tables for probability values for chi-square, with one degree of freedom, the value of chi-square for a probability of 0.05 is 3.84 . Since the observed value is 5.14 , a probability value less than 0.05 is proved, $\mathrm{p}<0.05$, significant.

\section{DISCUSSION}

In this study, 44 were female and 6 were male with a F: M ratio 7.3: 1. Literature reviews have shown that CTS is three to four times more common in females and is thought to be in part to occupation. ${ }^{2-4}$ CTS has been shown to be common in occupations that have been filled predominantly by females like food processing, food manufacturing, and construction works are closely associated with CTS.5-7 All these jobs may involve forceful repetitive twisting and turning movements of wrists which may result in repetitive strain injuries to wrists in the long run.

In this series, gender ratio is much more than the western series, this may be related to the more manual jobs that our females engage, which demand more forceful repetitive movements of wrists than their western counterparts where they depend more on machines for performing household jobs. In this series, majority of women belong to construction fields, prawn peeling and home making jobs. Majority of cases $(44 / 50)$ belong to $30-60$ years age group, this is in full agreement with the Literature. ${ }^{8}$ CTS is predominantly a disease of 30s or 40s. This shows the importance of years of Occupational exposure in revealing the symptoms. Hence, CTS is considered as one among the group of repetitive strain injuries.

Hand dominance is relevant in CTS; since CTS occurs more frequently in dominant hands. If it is present bilaterally, symptoms are more predominant on the dominant side, hence in this series wrist measurements were taken on the dominant side only. Wrist thickness (T) and wrist width (W) 
are taken at the level of distal crease to calculate $\mathrm{T} / \mathrm{W}$ ratio (Johnson's index) ${ }^{9}$.

In this series, $\mathrm{T} / \mathrm{W}$ ratio is $\geq 0.7$ in $92 \%(46 / 50)$ and $<0.7$ in $8 \%(4 / 50)$ ( $\mathrm{p}$ value 0.00$)$. Wrists having $\mathrm{T} / \mathrm{W}$ ratio $\geq 0.7$ are called circular wrists (squarer wrists) and those with $<0.7$ are called as rectangular wrists.

In the circular wrist group, $95.7 \%$ got significant DL for sensory studies to suggest CTS. In the rectangular wrist group, the \% with significant motor and sensory latency is only $50 \%$.

This difference in percentages between two groups has got confirmed statistical significance ( $p$ value $<0.05$ ) as shown in this study and hence $\mathrm{T} / \mathrm{W}$ ratio is relevant in the evaluation of patients with CTS. Johnson et al in 1983 were the first to correlate wrist dimensions and median nerve latencies. ${ }^{10} \mathrm{He}$ could demonstrate that a wrist ratio of 0.7 may be critical shape of wrists at which latencies tend to reach the upper limit of normal. ${ }^{11}$

Studies done by Gordon et al, ${ }^{12}$ Edwards, ${ }^{13}$ Nathan et al ${ }^{14}$ showed that estimation of $\mathrm{T} / \mathrm{W}$ ratio of prospective employees during pre-placement examination is highly significant. Edwards could demonstrate that of the 100 employees who has got Wrist ratio of 0.75 and above, 99 developed CTS within 6 months. Nathan et al found that wrist ratio (WR) was third risk factor for CTS; age being first and BMI being second for slowing of sensory conduction of median nerve in longitudinal study of CTS in Industry.

Radecki $^{15}$ is also agreeing with the fact that women had larger average wrist ratio than males and these patients had prolonged Median DL with a higher average wrist ratio than those of each gender without a median nerve sensory abnormality. Radecki ${ }^{16}$ could demonstrate that the relationship between Average wrist ratio and the likelihood of median abnormality appeared to be not affected by occupation.

According to Khulman and Hennessy, ${ }^{17}$ wrist squareness ( $\mathrm{T} / \mathrm{W}$ ratio $\geq 0.7$ ) is the most objective sign in CTS because it is not based on subjective complaints and is not consciously influenced by subjects. Hence, measurement of $\mathrm{T} / \mathrm{W}$ ratio should be made mandatory for employees during preplacement examination.

Prompt recognition of persons with the risk factor i.e. $\mathrm{T} / \mathrm{W}$ ratio $\geq 0.7$ can provide timely treatment for the employee and this can save the time and energy of both employers and employees. Repetitive motion of wrists in the work place can result in the development of CTS in as short a time as 2 weeks; particularly in people with this risk factor for CTS.

\section{CONCLUSION}

This small study could demonstrate the following findings-

1. Our females are more prone to CTS than their western counterparts. This has been shown by a higher femaleto-male ratio of incidence.

2. CTS is predominantly a disease of middle age i.e., 30-60 years; this is in par with western studies.

3. Wrists of females are more circular (with $\mathrm{T} / \mathrm{W}$ ratio $\geq 0.7$ ) than males.
4. Statistically significant association is present between circular wrists with $\mathrm{T} / \mathrm{W}$ ratio $\geq 0.7$ and prolonged median sensory latency ( $\mathrm{p}$ value $<0.05$ ).

5. Johnson's index (WR) $\geq 0.7$ ) is a useful predictive factor in the diagnostic evaluation of patients with suspected CTS.

6. Measurement of T/W ratio should be made mandatory during pre-placement examination of jobs involving forceful repetitive movements of wrists. This can save a lot of time and money for both employer and employees.

7. For patients with Johnson's index $\geq 0.7$, an electrophysiological diagnostic study should be made mandatory within six months entering a high risk job for the early detection of CTS.

\section{REFERENCES}

[1] National Health and Medical Research Council. Occupational health guide on repetitive strain injuries, 1982.

[2] Kopel HP, Goodgold J. Clinical and electrodiagnostic features of CTS. Arch Phys Med Rehab 1968;49:371-5.

[3] Radecki P. The familial occurrence of CTS. Muscle Nerve 1994;17(3):325-30.

[4] Reinstein L. Hand dominance in CTS. Arch Phys Med Rehabil 1981;62(5):202-3.

[5] Bernard BP. Musculoskeletal disorders and work place factors: a critical review of epidemiologic evidence for work related musculoskeletal disorders of the neck, upper extremity and low back. National Institute for Occupational Safety and Health, Cincinnati: National Academy Press 1997.

[6] Roquelaure Y, Mechali S, Dano C, et al. Occupational and personal risk factors for CTS in industrial workers. Scand J Work Environ health 1997;23(5):364-9.

[7] Braddom RL. A text book of physical medicine and rehabilitation. Chapter 48. $3^{\text {rd }}$ edn. Saunders 2007:1079-80.

[8] Phalen GS. Reflections in 21 years' experience with Carpal tunnel syndrome. JAMA 1970;212(8):1365-7.

[9] Kouyoumdjian JA, Morita MP, Rocha PR, et al. Wrist and palm index in CTS. Arquivos de Neuropsiquiatrica 2000;58(3A):625-9.

[10] Johnson EW, Gates T, Poindexter D, et al. Wrist dimensions: correlation with median sensory latencies. Arch Phys Med Rehab 1983;64(11):550-7.

[11] Johnson EW, Gatem, Poindexter D, et al. Wrist dimensions: correlation with median sensory latencies: Arch Phys Med Rehab 1985:64:556-7.

[12] Gordon C, Johnson EW, Gatens PF, et al. Wrist ratio correlation with CTS in industry. American Journal of Physical Medicine and Rehabilitation 1988;67(6):2702.

[13] Edwards KS. Square wrists and CTS. Ohio Med 1990;86(6):432-3.

[14] Nathen PA, Keniston RC, Myers LD, et al. Obesity as a risk factor for slowing sensory conduction of median nerve in industry. A cross sectional and longitudinal study involving 429 workers. J Occup Medicine 1992;34(4):379-83.

[15] Radecki P. A gender specific wrist ratio and the likelihood of median nerve abnormality of the carpal tunnel. American Journal of Physical Medicine and Rehabilitation 1994;73(3):157-62. 
[16] Radecki P. Variability in median nerve and ulnar nerve latencies: implications for diagnosing entrapment. Journal of Occupational Environmental Medicine 1995;37(11):1293-9.
[17] Khulman KA, Hennessey WJ. Sensitivity and specificity of CTS signs. American Journal of Physical Medicine and Rehabilitation 1997;76(6):451-7. 